molds the developing organism so uniformly true to type, and of the condition which now and then may cause the development of an individual in some detail to halt a little short of, to over-run, or otherwise to deviate from its due course.

It is truly an obligation, very generally neglected by American entomologists however, to record each example of insect teratology simply and directly, just as it is observed; but the fulfilment of this obligation is by no means accompanied by any additional obligation to offer at the same time an explanation or interpretation of the phenomenon. Indeed, in the present state of our knowledge of such phenomena any attempt to interpret individual examples is rarely demanded, or even scientifically justifiable.

\title{
THE SECOND ABDOMINAL PLEURITE IN THE HIGHFR COLEOPTERA
}

\author{
By W. T. M. Forbes, \\ Cornell University, Ithaca, New York.
}

It is generally recognized that the first sternite of the abdomen is membranous in all the holometabolous insects. As to the first pleurite and the second segment there takes place a gradual reduction, which reaches such a stage that in the majority of Coleoptera the first two segments are represented by a more or less membranous dorsal and spiracular region only.

The usual statement is that the first segment of the abdomen has atrophied, and that the second is ventrally absent and laterally fused with the third. An examination of fresh specimens shows that this is not strictly the case. In fact the second pleurite may disappear in at least two different ways.

In the Bostrychiformia (Fig. 1, A) the first stage seems to have been an infolding of the whole subspiracular region of the first two segments, so that the hind coxa comes to lie against the anterior edge of the third segment or even overlap it somewhat. In this way the two segments are completely buried from view, and their sclerites become more or less completely de- 
chitinized, except on the mid-ventral line where the second segment takes the form of a strong keel, filling the space between the coxæ. The second pleurite is frequently completely membranous, but in the species figured (Trypopitys) it still shows some feeble chitinization and even a few rudimentary hairs

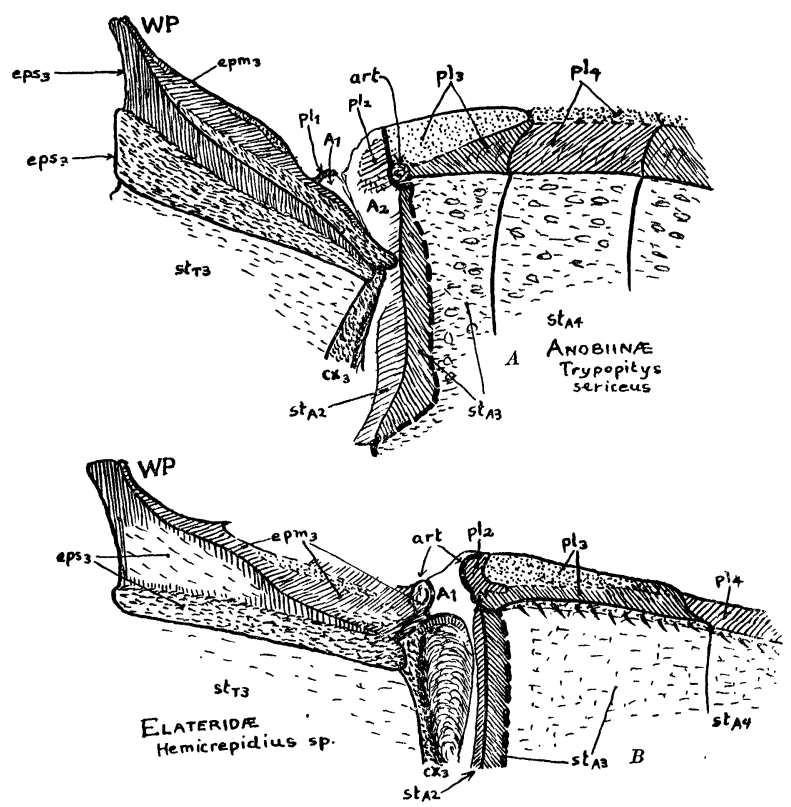

Fig. 1.

Each figure gives a ventro-lateral view of the junction of thorax and abdomen, with the articulation separated to expose the membranous structures. The variously shaded areas represent sclerites, the plain white, membrane. Hairy surfaces indicated, pads for the reception of the elytra stippled, the plain chitin striated.

$A_{1}$ Membranous first sternal region of abdomen. $A_{2}$ Membranous second sternal region of abdomen. eps $s_{3}$ Metepisternum (the hairy ventral portion only is exposed when the elytra are closed). $\mathrm{epm}_{3}$ Metepimeron (apex uncovered in Trypopitys, wholly covered in Hemicrepidius). $\mathrm{pl}_{2}, \mathrm{pl}_{8}$, $\mathrm{pl}_{4}$ Pleurites of successive segments of abdomen. $\mathrm{pl}_{1}$ rudimentary chitinous nodule, perhaps representing the first pleurite. st t $_{3}$. Metasternum of thorax. $\mathrm{st}_{\mathbf{A} 2}$, st $\mathrm{st}_{\mathbf{A} 3}$, st $\mathrm{At}_{\mathbf{A} 4}$ Successive sterna of abodmen. art. Articular facets inlicating the junction of metepimeron and second (or third) pleurite. WP Wing process. Heavy solid line. Edge of superficial portion of pleura, adjoining pleura of thorax in life. Heavy broken line. Edge of coxal cavity on surface of third sternite.

Fig. 1, A. Bostrychiformia, Anobiidæ. Trypopitys sericeus.

Fig. 2,B. Serricornia, Elateridæ. Hemicrepidius species. 
$\left(\mathrm{pl}_{2}\right)$. The first visible pleurite in this case then is wholly formed of the third segment.

On the other hand an elater (Fig. 1, B) shows clear evidence of the fusion commonly assumed. The second pleurite is very small $\left(\mathrm{pl}_{2}\right)$, but lies completely flush with the surface of the body and forms the actual articular surface facing the metepimeron. The suture is traceable dorsally, and continuous with the well marked fold between the second and third dorsal segments, but it soon becomes ambiguous, and I am not sure I have indicated its course correctly.

The obvious conclusion from this is that the loss of the second pleurite has taken place twice independently (at least), and that its absence is not necessarily an indication of a homogeneous series of "higher Coleoptera." In fact the presence of forms with a well marked second pleurite is known in both series (Omethes, for instance in the Serricorns besides the possibly degenerate Lampyridæ; the early Dascyllidæ in the Bostrychiform series).

Incidentally it appeared in this work that the common statements as to the number of free segments of the abdomen are not correct. In the elater only the last segment is free, while in Trypopitys the entire abdomen is ankylosed, even the sutures being obliterated, except the first. This is correctly stated in the descriptions of the genus, but not allowed for in any key I have seen. 

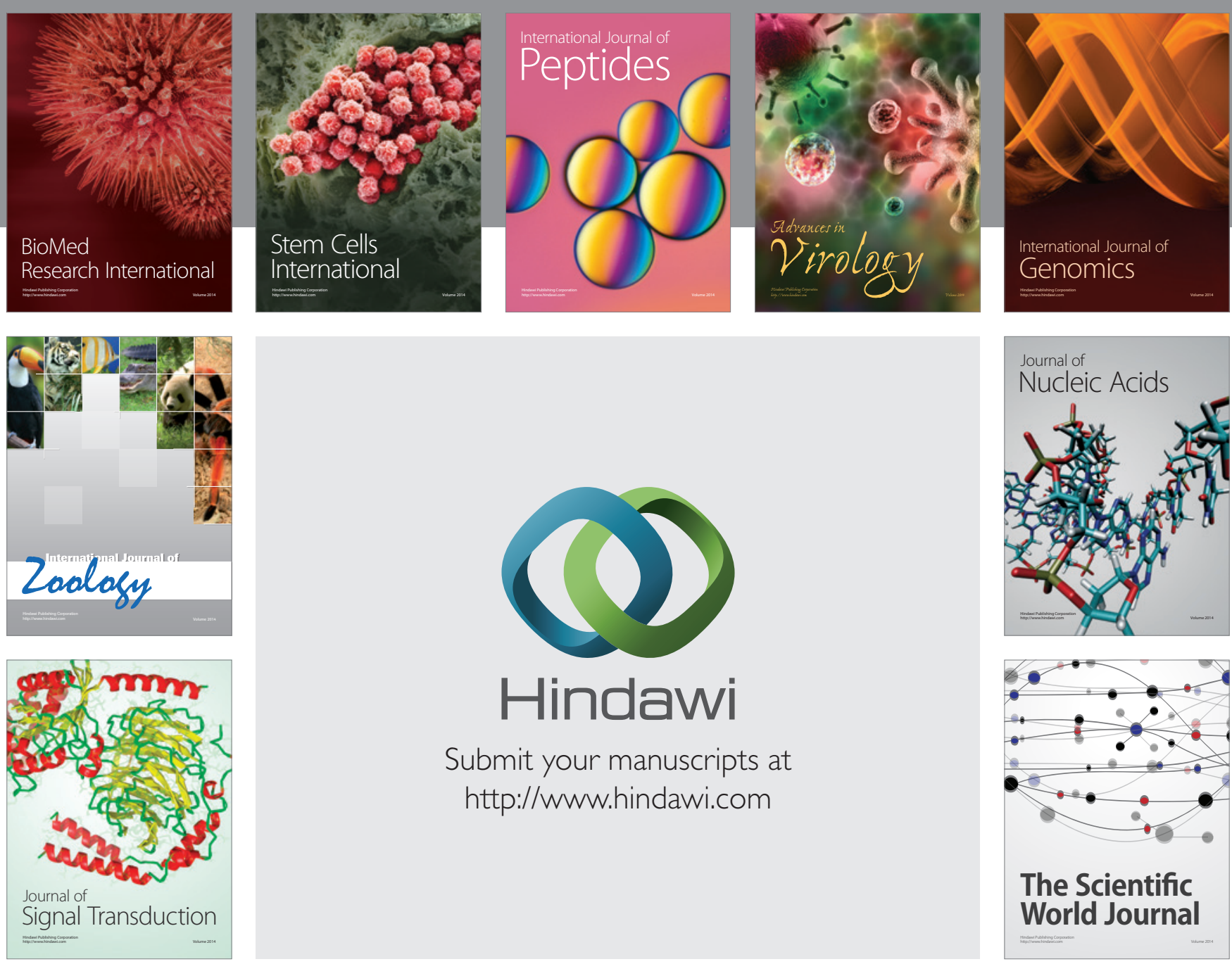

Submit your manuscripts at

http://www.hindawi.com
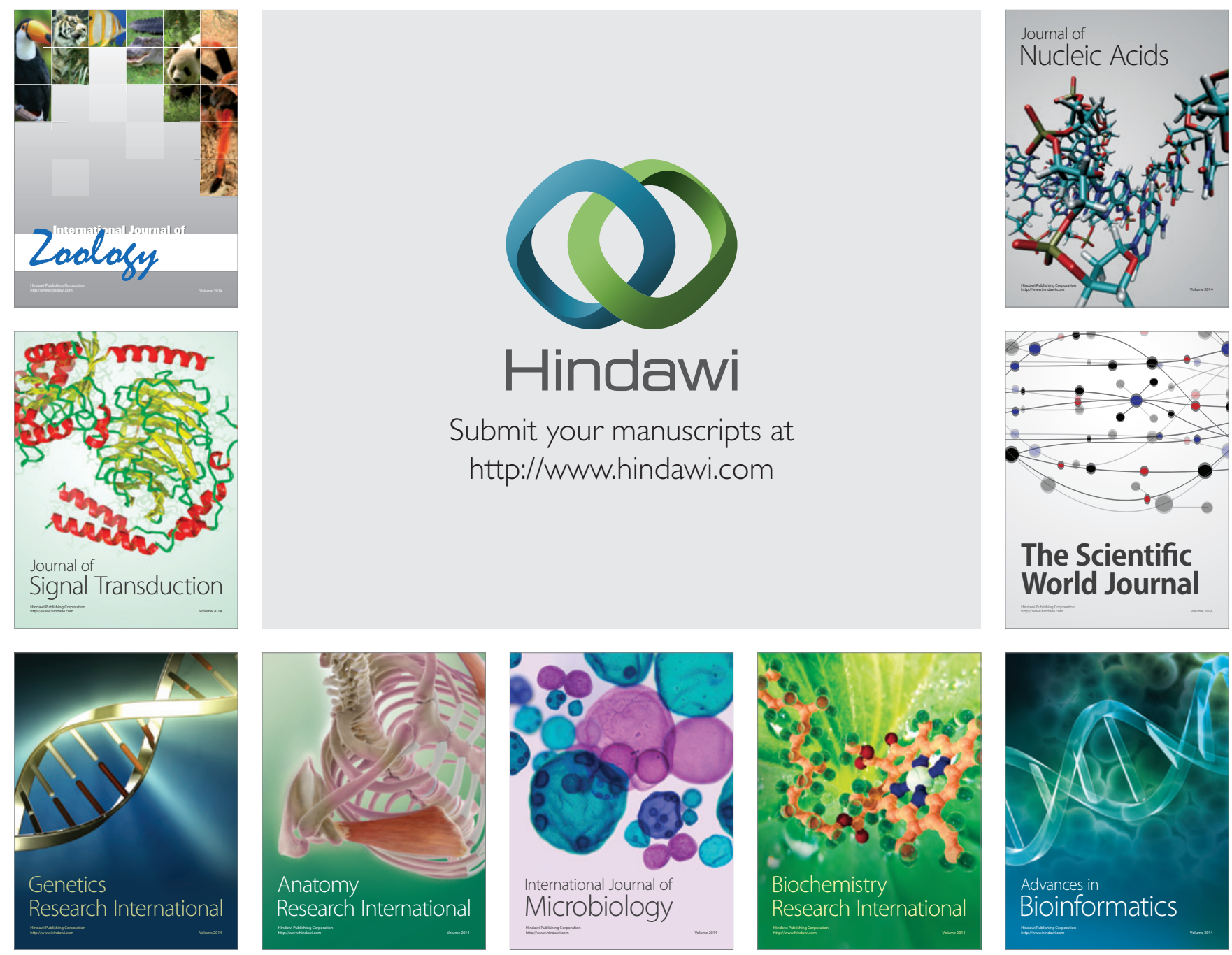

The Scientific World Journal
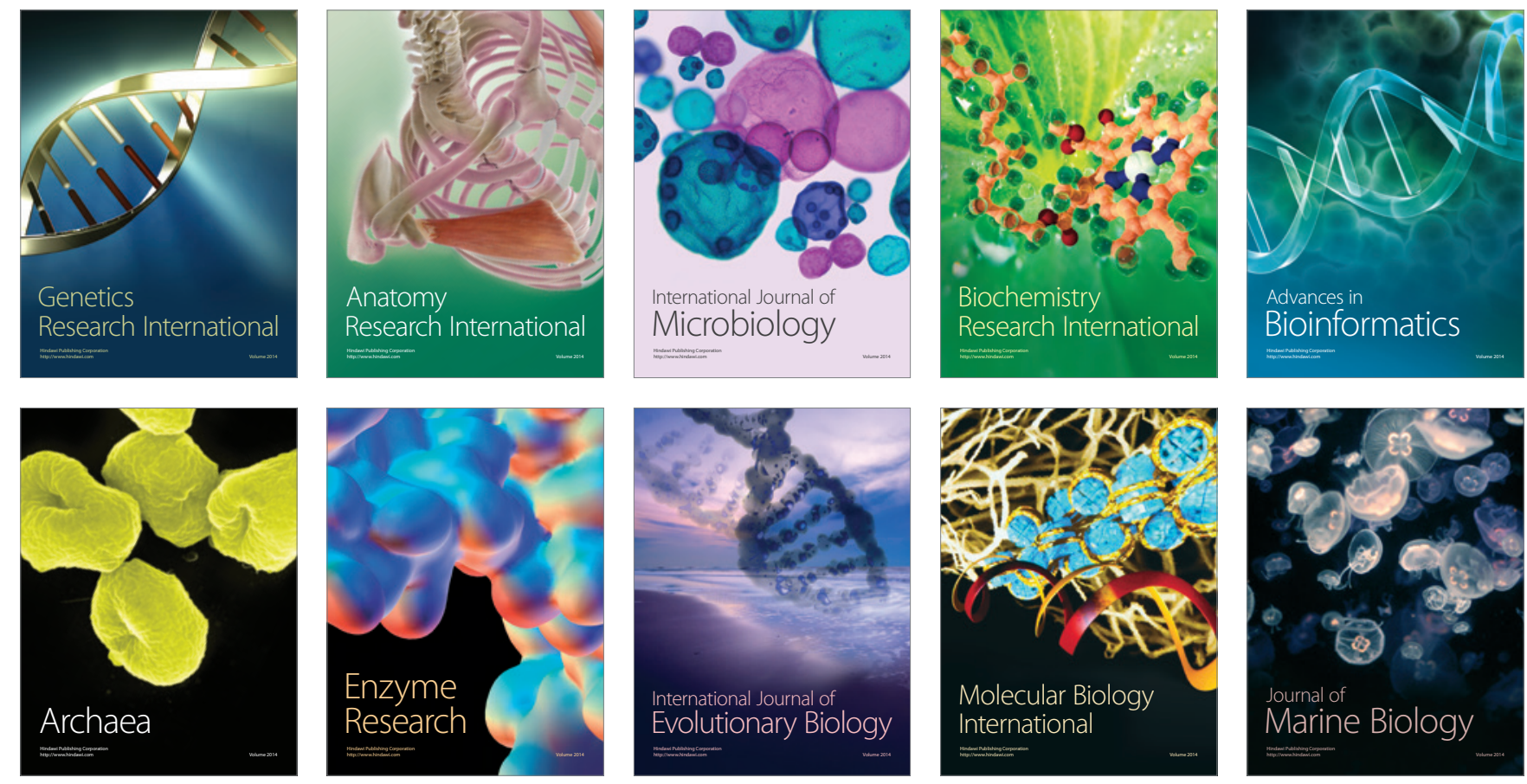